\title{
1 \\ Living the Social Determinants of Health: My Story
}

Angelina Joshua

My name is Angelina Joshua and I was born in 1987 in Ngukurr. Ngukurr is a small community in south-east Arnhem Land. It takes about eight hours to drive from Ngukurr to Darwin and our nearest large town is Katherine, or K-Town to the locals. I'm the youngest child in our family. There are seven of us: two older brothers and four older sisters. My mum was from Oenpelli, an Aboriginal community near Kakadu, and my dad was from Ngukurr.

When I was little, I remember always being with my brothers and sisters; they were always home and looking after me. They gave my dad time to do his job and to put food on the table. Growing up, my life was the best. I wouldn't ask for anything else, because I have an amazing family. I also remember going to school; I went nearly every day because my dad said it was important. Sometimes I didn't want to go, but I didn't have any choice; I had to go.

My mum passed away when I was about seven. I don't remember her at all, but sometimes I think about going to visit her country around Oenpelli. Dad had to look after us, but he had my older brothers and sisters and my three grandparents to help. They had to help because he often had to leave Ngukurr for meetings. Dad was the housing officer and before that he was the town clerk. 
I was going to school every day, but I didn't ever learn to read and write as a child. It wasn't until I was in high school that I finally learnt to read: I was 13 or 14 . A new teacher came in and brought literacy and numeracy into the school. We did writing on the board and we read the book Lockie Leonard (Winton 1990). We did that book in school and it was really amazing when I actually learnt to read-this was when I was 14. It was really hard at first. I was always saying 'I don't know this word, I don't even know what it means'. It was really hard man. I look back at it now and it's hard to imagine not being able to read. I love reading.

My dad was the boss in our family. He was strict in a good way. I'd say to him, 'I want to go to the disco', and he would stop and have a think and then say, 'No you are staying at home'. He wouldn't give me the opportunity to go out prowling at night. I didn't have a boyfriend; I wasn't allowed to have a boyfriend. No boyfriends and no prowling. I didn't like it much then, watching all my friends walk about at night. Now I think it was good to be different. Now when I'm at Ngukurr, I look at all the girls and boys, all my old friends, and they all married up now with kids. I don't know how they feel; they are always caught up with their kids who are crying all the time. But I'm free. I see boys telling their wives what to do and if they don't do it, they get beaten. I am lucky because of my dad. I thank my dad for raising me up to be a talented woman. There is one thing I worry about; I didn't learn much about culture. ${ }^{1} \mathrm{My}$ dad was more interested in me learning at school than teaching me things about culture.

When I was 13, my dad got married again. I didn't feel comfortable calling someone new 'mum'. Actually I didn't feel comfortable at all, because I had grown up without a mother. We lived with her and her three kids; sometimes there were 10 children in the house. I was lucky that I had other family to stay with in Ngukurr and I could get away sometimes when it felt really overcrowded and noisy. Now the kids are part of the family; we have all grown up and we understand.

When I was 16, I went to boarding school in Darwin. I wouldn't say it was difficult. It was alright, even normal. There were lots of kids from different communities there. Sometimes we would fight, but not as much as the fighting that goes on now. But maybe I had too much fun at boarding school. I got expelled for being a bad girl and going out and looking

1 By culture, Angelina means traditional Aboriginal culture, including knowledge of her country and dreamings, knowledge of her obligations through kinship as well as the appropriate songs and dances. 
for alcohol. I was always looking for alcohol. I would meet my friends and it was amazing; we would do this and that and I was the leader. My friends would all follow me and that's why I got caught all the time. I didn't really learn much. I had a bad attitude and I gave the house parents and teachers a bad time. They would say 'you are a talented young lady, I know you can learn and listen more, you've just got that attitude woman!'

It was a lot of fun, but I got expelled and got sent back home. Dad was really cross with me. He went to his office without talking to me and when he came home he said: 'Tomorrow you have got to look for a job, you are not going to eat and sleep under my roof and not work for a living'. I was just about to turn 18 .

So, I went and got a job as an assistant teacher at the school. I loved the kids and they loved me, but I didn't really know what I wanted to do. I was always thinking about other jobs. I worked at the council for a bit and then I ended up with lots of jobs around the community; I just kept moving from one to another. I left work for a while and I couldn't find another job, so I was at home doing nothing. Then a position came along with Sunrise Health Service. They were running a nutrition program in the community, where they gave iron supplements to children. They had a vacancy for a community-based worker. I took that job in 2005 and I have been eight years on and off with that mob.

Then, one day, something really big and bad happened to me. I had been in Darwin and Katherine for training for the nutrition project. It was the last day and we were at the resort in Katherine and we were drinking. I had a couple and I fell and I started having a seizure. It was lucky I was with my friends; they rang my supervisor and she came running. The ambulance came and took me straight to Darwin and straight into the operating theatre. They cut my head open and I had an operation to drain out all the blood. I was in a coma. Then they flew me to Adelaide while I was still in a coma. When I woke up, I couldn't remember anything, not anything, not even my name or what had happened to me or my age. My brother came down to Adelaide to look after me.

The accident affected my memory and my right leg. I remember being in hospital fighting for my memory and trying to walk again. It was the scariest thing for my brother. I don't know if it was scary for me because I felt so supported; my brother was there and my teacher, Jacinta, drove all the way from Melbourne to be with me. They were supporting me and 
my family all the way until I got strong again. I don't know what I would do without Jacinta. The best day of my life was when I was able to take steps again. That's when my physio organised another doctor to work with me and throw my walking frame away. We went to the gym to do some work and they said 'time to get rid of the frame'. I started to get really scared. I thought I might fall and bump my head again. But they did a good job; it was amazing. They said: 'I'm going to do this and you copy me'. They were hopping and running and I thought 'Oh my gosh, I can't do this', but they said, 'Yes you can, just take it slowly'. I thought he was crazy, but I took my first two steps and it made me feel really good inside. I just went for it. I was proud of myself; it was the best thing that ever happened in my life to walk again. I still remember it and think about it. I walked back to my room and I didn't use the frame. My brother saw me sitting there with a big smile saying, 'We are going back home'.

The accident changed my life. Before the accident, I was a really heavy smoker and I drank a lot of alcohol. It was heavy drinking. I drank all the hot stuff: rum, Jim Beam, vodka. I was drinking so much, but I was just being me. It was nothing to do with being worried; I just liked drinking and being drunk. But maybe if I didn't have such a good family, I would be drinking because of stress-lots of people do. Now I'm a new person. I get up early in the morning and I go to work.

When I came home to Ngukurr, my memory wasn't that strong, but gradually it all came back; being home really helped. I started work again and I had lots of opportunities including the opportunity to go and live and work in Darwin. In 2013, I lost the most important people in my life. I lost my dad, he was 58 , and my grandma. It was so much pain. I couldn't think or work; I was really, really down. Then another girl died and it was all too much. She was so young and the loss of her really hurt. I couldn't keep going. I kept getting these voices in my head. Dad's voice kept me from breaking loose. I was going backwards. Losing my dad was really painful. I was living in Darwin and I wanted to experience new things, but my family were calling me, calling me back home. They were saying 'It's not the same without you'. It made me really sad. I missed my best friends, hanging out with them and laughing, and I missed my brothers and sisters. I didn't have anyone to talk to. It was a really hard time. I was experiencing city life, but I didn't really like it. At least I gave it a go. 
It's good to be back home in Ngukurr; being home is just great. I didn't work for a month and then I said to myself 'I need to be thinking and working for my brain to work again'. A linguist came to my place and said that they were looking for a part-time language worker. I said that I'd love to do that because I didn't have any job. Now I have a part-time job at the Language Centre. The hours suit my life. I don't want to work full time and get stressed and hurt my brain again. It's fascinating because we are learning my grandma's language.

I am living with my sister, but I would love a place of my own. My sister has three kids and they all bring their friends around and make a lot of noise, which drives me crazy. I wish that the house wasn't so crowded; it gets so hard, especially when you want to use the stove and the shower. It's a good life now, though. I'm feeling calm after lots of ups and downs. It's so much better than when I was drinking and smoking and had all that attitude.

\section{References}

Winton, T. 1990. Lockie Leonard Human Torpedo. UK: Bodley Head Children's Books. 
This text is taken from Indigenous Australian Youth Futures: Living the Social Determinants of Health, edited by Kate Senior, Richard Chenhall and Victoria Burbank, published 2021 by ANU Press, The Australian National University, Canberra, Australia.

doi.org/10.22459/IAYF.2021.01 